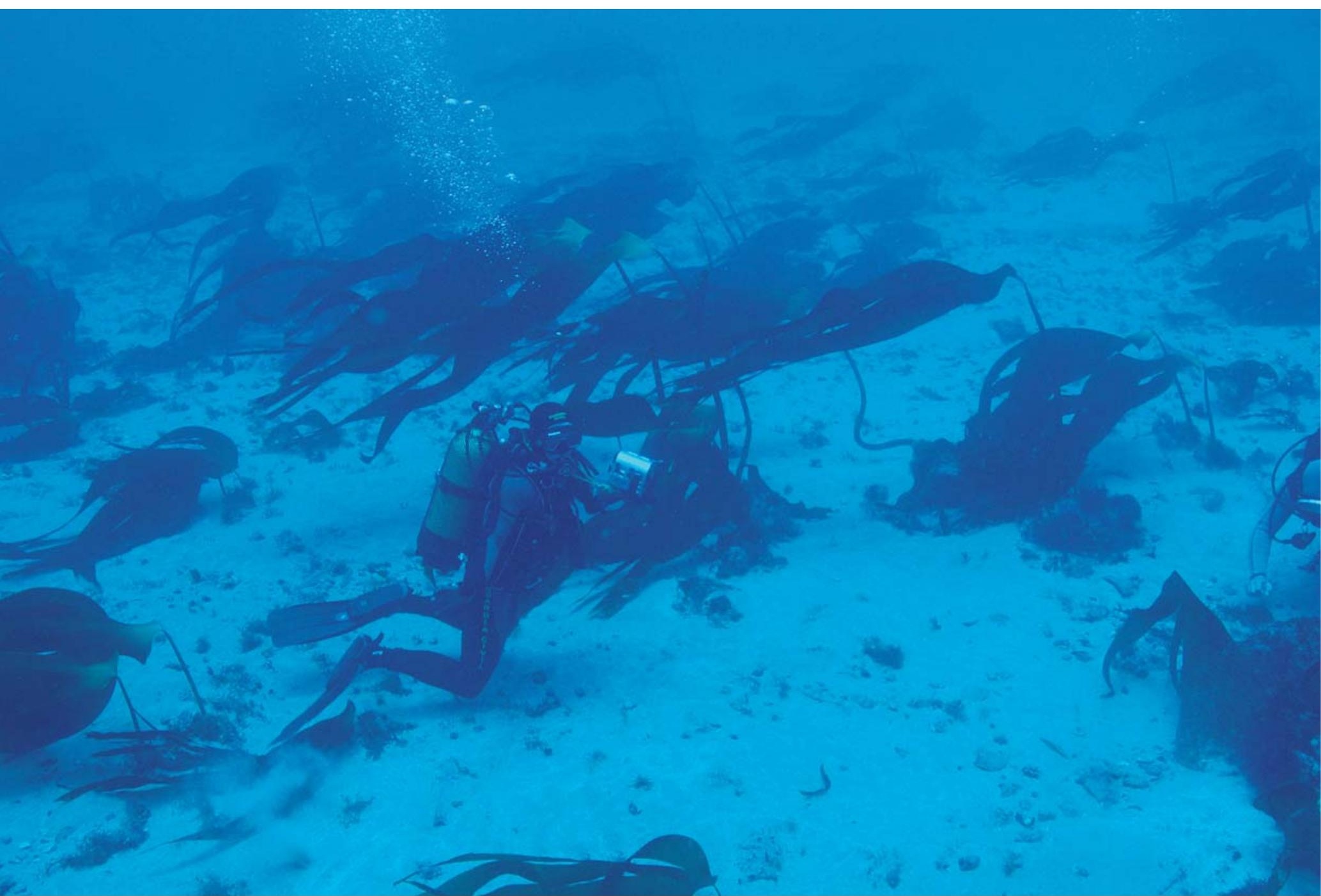

Las Laminarias. Foło: Fondo Gráfico IAPH-CAS (Mercedes Gallardo Abárzuza, de todas las imágenes del artículo, salvo que se especifique lo contrario)

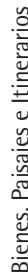




\section{El patrimonio arqueológico subacuático}

\author{
Milagros Alzaga García, Cristina \\ Guerrero López, Aurora Higueras- \\ Milena Castellano, Josefa Martí \\ Solano, Centro de Arqueología \\ Subacuática del IAPH
}

El Campo de Gibraltar es una comarca de la provincia de Cádiz situada en el extremo sur de Andalucía, y formada por un total de siete municipios: Algeciras, Los Barrios, La Línea de la Concepción y San Roque ocupan el espacio geográfico de la bahía de Algeciras. A estos cuatro municipios costeros hay que sumar el de Tari$\mathrm{fa}$, con su orientación marcadamente atlántica. Se añaden, como municipios interiores, los de Castellar y Jimena de la Frontera.

La ubicación estratégica de este entorno, en la zona de paso que forma el Estrecho de Gibraltar, ha marcado el devenir histórico de las poblaciones que se han ido asentando a orillas de sus aguas desde la más remota antigüedad. El comercio, el paso de personas de una a otra orilla y la actividad pesquera han servido de hilo conductor a lo largo de toda la historia, a lo que se le pueden unir dos condicionantes geográficos que han marcado su evolución histórica:

- El hecho de estar situada y condicionada por el Estrecho de Gibraltar, que pone en relación directa dos mares (el Atlántico y el Mediterráneo) y dos continentes (Europa y África). Las grandes rutas de navegación y comercio, a lo largo de toda la historia, han utilizado esta autopista marítima cuya travesía se caracteriza por ser un paso de difícil navegación, con corrientes y vientos extremos que requerian de unas condiciones óptimas para atravesarlo.

- La existencia en pleno Estrecho de una bahía natural con unas condiciones excelentes desde todos los puntos de vista: resguardo, aprovisionamiento, tenedero, riqueza piscícola, etc.

Por lo tanto, como lugar de tránsito y asentamiento de diferentes culturas desde la prehistoria hasta la actualidad, son abundantes los testimonios y la huella de esta presencia en los numerosos yacimientos arqueológicos localizados tanto en tierra como en el mar, circunstancia que ha posibilitado que en la actualidad podamos disfrutar de un importante y abundante legado arqueológico.

Con respecto al patrimonio arqueológico localizado en el ámbito marino se debe señalar que su localización, identificación y evaluación se ha llevado a cabo por medio de diversas actuaciones y proyectos, cuyos resultados se han visto plasmados en la Carta Arqueológica Subacuática de Andalucía. Ya en los años 1982 y 1983 se acometieron las primeras prospecciones en la ensenada de Bolonia, y en el 84 se comenzaron los trabajos en la bahía de Algeciras, entre Punta Carnero y Getares, importante enclave en pleno Estrecho de Gibraltar.

En el año 1999, desde el Centro de Arqueología Subacuática del Instituto Andaluz del Patrimonio Histórico, se llevó a cabo una prospección con sondeos en la ensenada de Bolonia y, en el año 2000, se desarrolló un proyecto de prospección arqueológica en la isla de Tarifa.

La Carta Arqueológica Subacuática de Andalucia se presenta por tanto como un instrumento indispensable para la protección del patrimonio arqueológico subacuático existente en una zona determinada, más aún si se tiene presente que este importante y frágil patrimonio se encuentra gravemente amenazado por diversas actividades legitimas que inciden negativamente sobre el medio marino en general y sobre el cultural en particular. Nos referimos a aspectos como la proliferación de grandes obras de infraestructura que afectan al medio marino: construcción de gaseoductos, puertos comerciales, parques eólicos marítimos, creación de nuevos puertos deportivos, regeneraciones de playas.

En este sentido, se debe señalar que el área marítima que baña la zona del Campo de Gibraltar dispone de unos instrumentos legislativos especificos que tienen su origen tanto en la defensa del patrimonio natural como cultural. Así, en el año 2003 se procedió a la declaración de parque natural del Estrecho de Gibraltar que comprende una superficie total de 18.931 ha, entre los términos municipales de Algeciras y Tarifa, de las cuales 9.247 ha corresponden a la superficie marina declarada.

El referido parque natural cuenta con un Plan de Ordenación de los Recursos Naturales (PORN) sobre cuyo marco se han constituido los objetivos del Plan Rector de Uso y Gestión (PRUG), instrumento mediante el cual no sólo se procede a proteger el 
patrimonio natural existente en su ámbito de aplicación sino que se formula, entre sus objetivos, la "protección, recuperación, fomento y difusión de los valores culturales y antropológicos que conforman la historia de este espacio natural".

Así, entre los criterios establecidos para la gestión de los recursos existentes en el parque se recogen de forma expresa los aspectos que deben contemplarse para la conservación del patrimonio cultural, entre los cuales se pueden destacar los siguientes:

"Cualquier actuación autorizable que incluya movimientos de tierra tendrá en consideración la existencia de yacimientos arqueológicos y su rango de protección, adoptando las medidas cautelares de protección necesarias para su conservación".

"La Consejería competente en materia de medio ambiente en colaboración con las administraciones competentes apoyará las iniciativas que tengan por objeto la investigación, protección, conservación y puesta en valor del Patrimonio Arqueológico Subacuático existente en el ámbito marino del espacio protegido".

De la misma forma, se establece que, con carácter general, para el uso social y las actividades vinculadas al medio natural "la práctica y el desarrollo de las actividades de uso público y turismo vinculado al medio natural se realizarán asegurando la conservación del patrimonio natural y cultural del espacio protegido". En este sentido, se ha llevado a cabo una importante labor encaminada a facilitar el acceso a los valores naturales y culturales existentes en la superficie maritima que conforma el parque. Entre las numerosas actividades llevadas a cabo se debe destacar aquélla que facilita dicho acceso tanto a las embarcaciones de recreo como a las empleadas para el turismo activo -como es el caso de las embarcaciones utilizadas para la práctica del buceo recreativo-, por medio de la colocación de una serie de estructuras de amarre o fondeos fijos que tienen como misión tanto la eliminación del garreo de las anclas como el impacto que producen dichos elementos de fondeo sobre un fondo de gran valor natural y cultural. Al mismo tiempo, estas estructuras permiten llevar a cabo un seguimiento de las alteraciones que pueden provocar estas actividades sobre el fondo marino.

En este sentido, se debe destacar la labor que los clubes de buceo de la zona están llevando a cabo desde el punto de vista de la protección tanto del patrimonio natural como cultural. Estos clubes se han convertido en instrumentos indispensables para facilitar a la población que así lo requiera el disfrute de los distintos valores que conforman este espacio natural, al mismo tiempo que se fomenta y promueve el desarrollo social, económico y cultural de la zona. Estas actividades que vinculan el ocio con el patrimonio cultural han servido a su vez para concienciar a los ciudadanos de la necesidad de

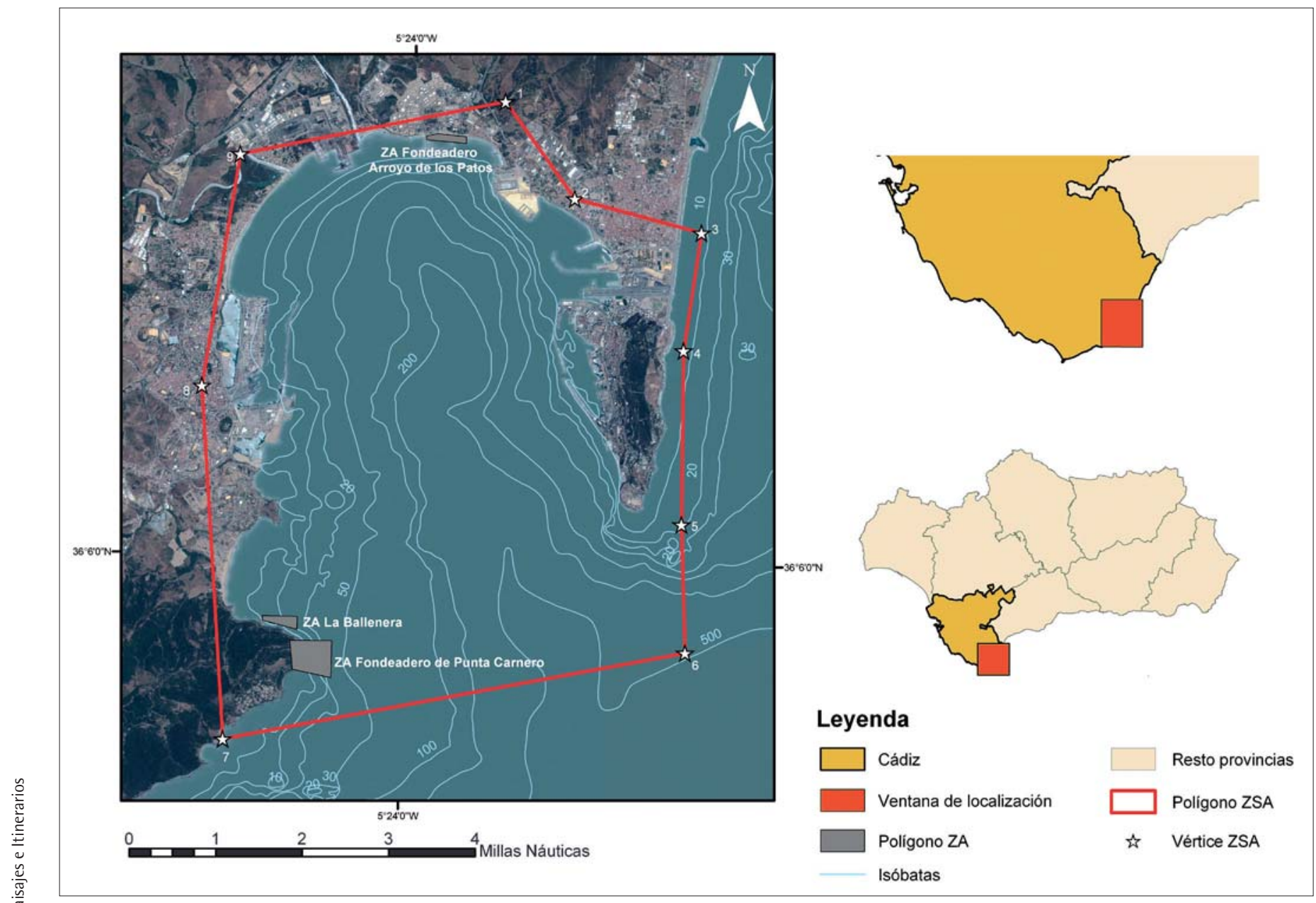

Zonas de servidumbre arqueológica en el Campo de Gibraltar. Fuente: Fondo Gráfico IAPH-CAS 
velar por este patrimonio, y asumir que todos podemos incidir positiva o negativamente sobre el mismo, más aún si se tiene presente que se trata de un patrimonio de una gran fragilidad, lo que hace indispensable mantener en equilibrio las condiciones que lo rodean. De la misma forma, se debe tener presente que una actitud negligente, ya sea por desconocimiento o de forma intencionada, pone en peligro la integridad de estos bienes, circunstancia por la cual la extracción de este patrimonio, si procede, debe estar enmarcada en un proyecto científico en el que participen profesionales cualificados y capacitados para la manipulación, traslado y restauración de este patrimonio, garantizando así tanto su integridad física como la información histórica que nos pueda proporcionar.

En por ello que, desde la Consejería de Cultura de la Junta de Andalucía y siguiendo lo establecido en la Convención para la Protección del Patrimonio Cultural Subacuático, promulgada por la UNESCO en el año 2001, se consideró necesario dotar, al patrimonio arqueológico subacuático localizado tanto en las aguas que bañan el litoral andaluz como en sus aguas continentales, de la protección jurídica establecida en la Ley de Patrimonio Histórico de Andalucía, a través de la delimitación de zonas arqueológicas y zonas de servidumbre arqueológica.

Así, tomando como base la información generada por el proyecto de carta arqueológica, desde la Dirección General de Bienes

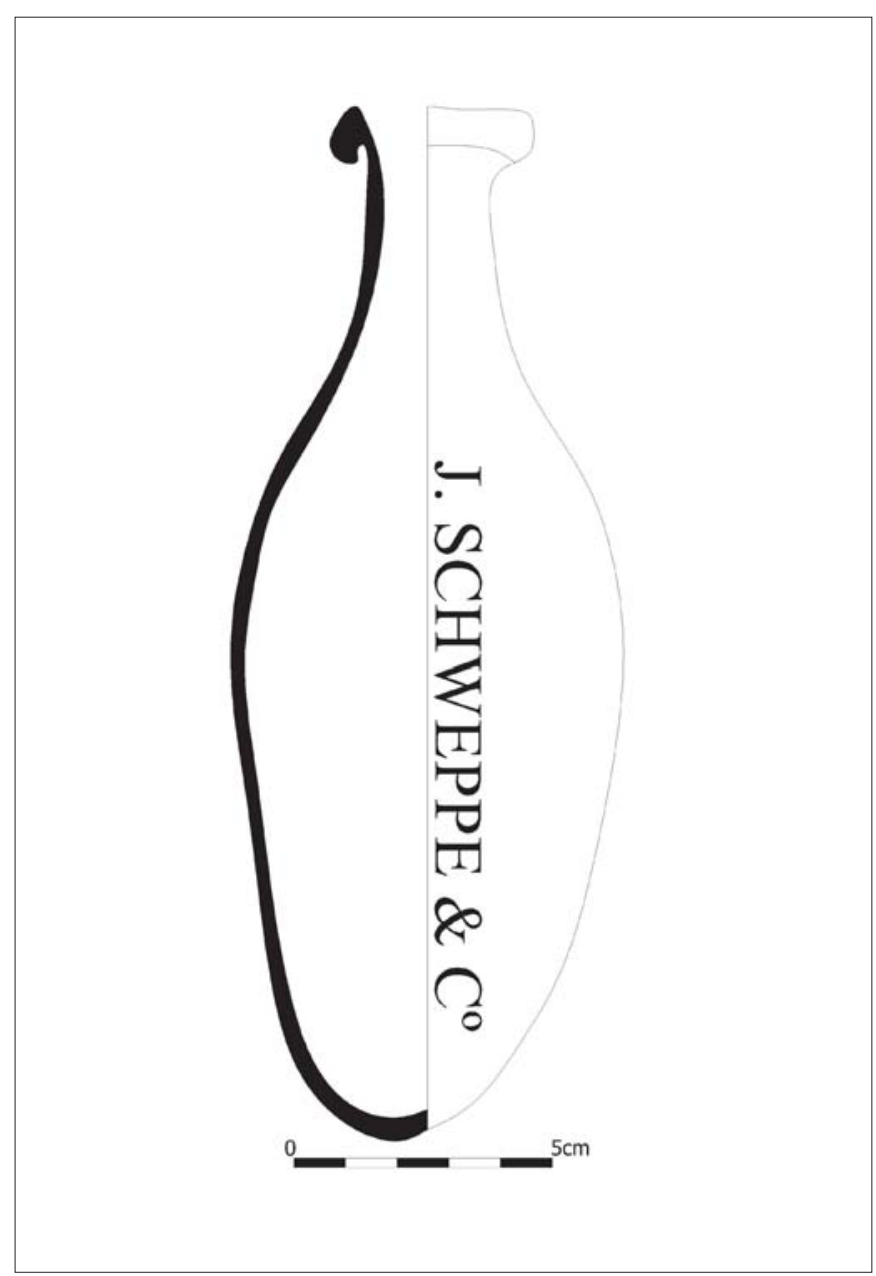

Botella Schweppe. Dibujo: Ernesto Toboso Suárez
Culturales en estrecha colaboración con el Centro de Arqueología Subacuática, se procedió a la inscripción, en el Catálogo General del Patrimonio Histórico, como Bien de Interés Cultural, de cincuenta y cinco zonas arqueológicas subacuáticas (BOJA n. ${ }^{\circ} 48$ de 10 de marzo de 2008) y a la declaración de cuarenta y tres zonas de servidumbre arqueológica (BOJA n. ${ }^{\circ} 63$ de 1 de abril de 2008).

En concreto, nueve de las cincuenta y cinco zonas arqueológicas inscritas en Andalucía se localizan en el ámbito marítimo del Campo de Gibraltar y cuatro de las cuarenta y tres zonas de servidumbre arqueológica declaradas se localizan en este mismo espacio, haciendo patente la importancia arqueológica subacuática de la zona, de la cual se pueden destacar los siguientes enclaves.

\section{La ensenada de Bolonia}

Área donde se ubica el asentamiento romano de Baelo Claudia y en cuyas aguas se han producido múltiples hallazgos ocasionales, y documentado varios naufragios -como los denominados bloques de piedra o cañones y ancla de Bolonia-. De la misma forma, se han localizado múltiples restos de fondeos de piedra de diversos tamaños que vienen a delimitar el área que, en época romana, era empleada para el fondeo de embarcaciones.

Son también visibles numerosos restos de bloques de piedra, tanto en las laderas como en el fondo marino, procedentes de la cantera localizada en Punta Camarinal. Se debe destacar también esta zona dado que, Punta Camarinal, desde el punto de vista de la navegación, constituye una franja de difícil navegación debido a los fuertes vientos y corrientes dominantes. Al mismo tiempo, su posición estratégica, en la ruta de navegación desde el Estrecho a las zonas atlánticas, hizo que fuera necesario construir torres vigias para asegurar las rutas de comercio.

\section{La isla de Tarifa}

En el entorno subacuático que rodea la isla de Tarifa se tiene constancia de la existencia de numerosos restos arqueológicos de diferentes cronologias y tipologías: desde la protohistoria hasta múltiples naufragios contemporáneos, tanto hallazgos aislados como pecios y fondeaderos.

Entre los distintos yacimientos existentes en la zona destacan los siguientes: el fondeadero nordeste de la isla de Tarifa, donde entre los 4 y 12 metros de profundidad se pueden contemplar, entre las rocas, numerosas anclas de piedra; el pecio San Andrés, denominado asi en referencia a las marcas que aparecian en unos lingotes de plomo localizados en la zona. Estos restos podrían ponerse en relación con el naufragio del vapor de palas Miño que se hundió en la zona en el año 1856 durante el trayecto que realizaba desde Málaga a Sevilla con objeto de que su pasaje asistiese a la feria de dicha ciudad. Los restos se localizan en un área que va desde los -17 a los -45 metros de profundidad. 


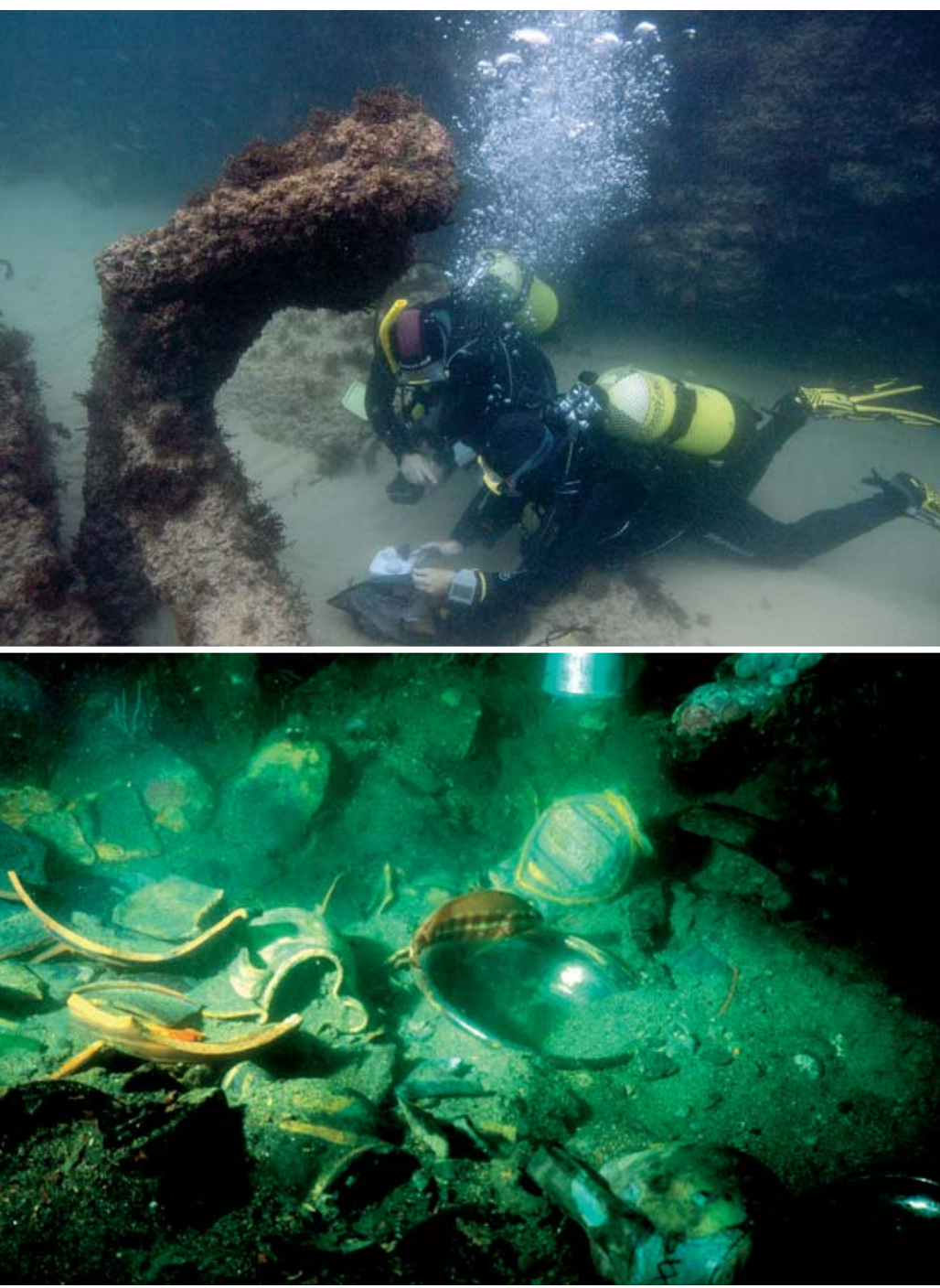

Trabajos de desconcreción en un ancla en Bolonia Cerámica del pecio de la ballenera. Foto: Manuel Martín Bueno

De este pecio diversos buceadores extrajeron unas botellas de vidrio con la marca J. Schweppe $\& \mathrm{C}^{\circ}$. Se trata de un tipo de botellas con una doble denominación: Hamilton, por ser este el nombre de su inventor, o Borrachas, dado que estos envases no podian colocarse en posición vertical y, por lo tanto, debian ser guardados en posición horizontal consiguiendo así que el líquido estuviese en contacto permanente con el corcho, manteniéndolo húmedo y evitando que la bebida perdiese carbonato.

\section{Piedras de molino de Punta Marroquí}

A una profundidad de 44 metros y dispuestas en torno a una gran piedra, se localizan siete piedras de molino de gran tamaño.

\section{Las Laminarias}

Entre los 30 y 35 metros de profundidad se encuentra, muy disperso, diverso material de cronología variada. Los datos proporcionados por la información oral indican que en la zona podrían haber existido restos de un naufragio de época romana cuyos elementos eran visibles en superficie. Sin embargo, en la actualidad y
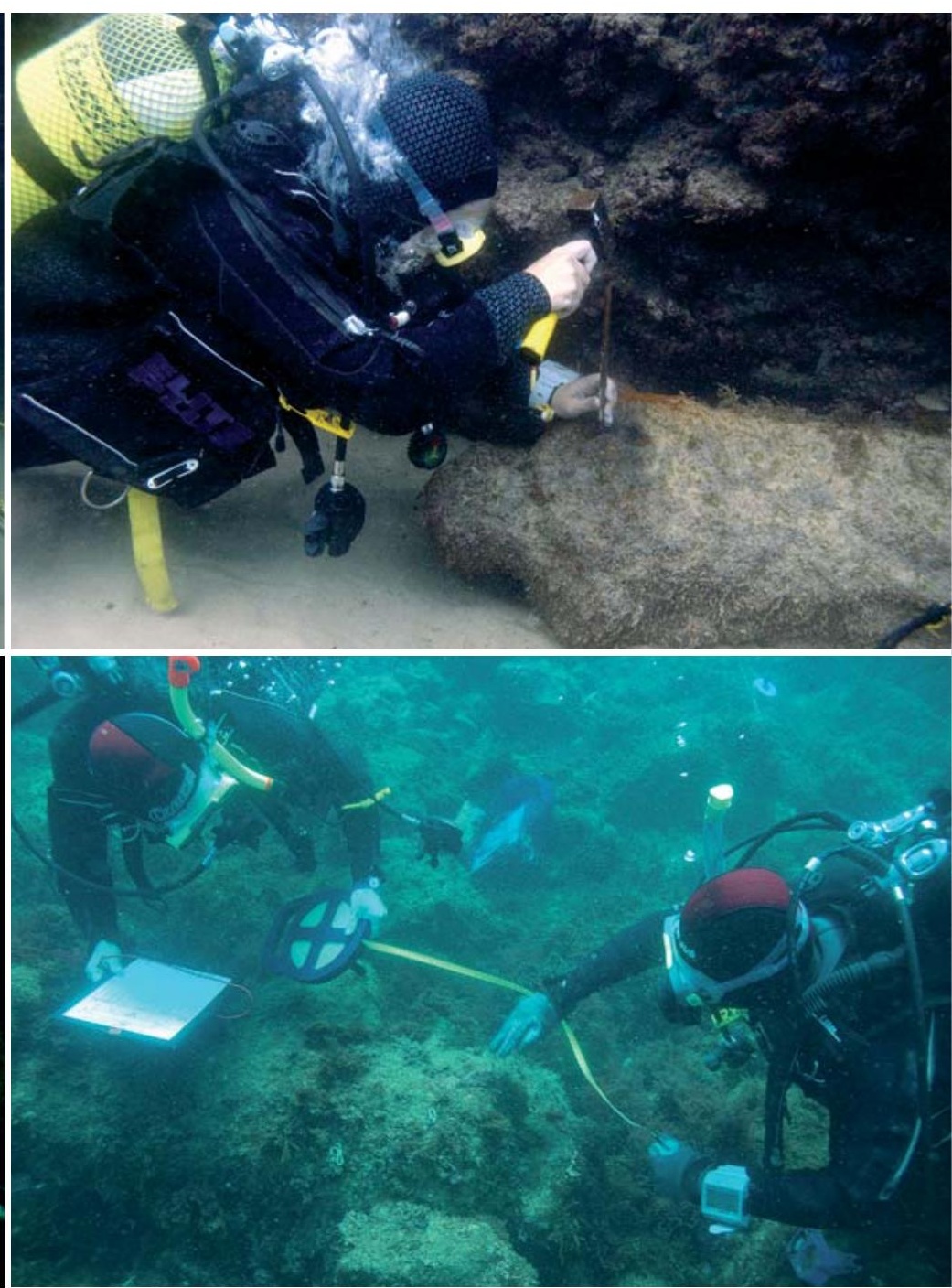

Trabajos de desconcreción en un cañón en Bolonia Medición de cañón en Algeciras

debido al fuerte expolio que ha sufrido la zona los materiales que se pueden visualizar son escasos y dispersos.

\section{Bahía de Algeciras}

La bahía de Algeciras cuenta, entre Punta Carnero y Punta Europa, con un espacio que ha sido empleado como área de fondeo por las embarcaciones que, bien procedentes del mar Mediterráneo o del océano Atlántico, han surcado estas aguas a lo largo de la historia, tal y como lo atestiguan los restos arqueológicos localizados en sus fondos marinos, entre los cuales se pueden destacar dos zonas: el pecio de la Ballenera, barco que cronológicamente puede enmarcarse entre finales del siglo XVI y principios del siglo XVII tal y como lo atestiguan tanto los restos cerámicos de procedencia italiana que transportaba el referido buque como los restos de artillería, lingotes de plomo o elementos de vidrio localizados; el fondeadero de Getares, donde la distribución de los restos de cepos localizados hacen pensar que esta zona era empleada como refugio por las naves en época romana, aunque tampoco se debe descartar la existencia de una almadraba en la zona. 
De la misma forma, a lo largo del tramo marino del Campo de Gibraltar se pueden contemplar diversos restos de naufragios acontecidos a lo largo del siglo XX, que vienen a atestiguar tanto la importancia de la zona como ruta imprescindible para la navegación como la peligrosidad de la misma, condicionada por corrientes, vientos y bajos rocosos que dificultan notablemente la travesía, haciendo que algunos de los buques que surcan sus aguas no lleguen a alcanzar el puerto de destino. Éste fue el caso de los barcos de vapor conocidos como pecio de las Calderas, pecio de las Gorgonias o El Citos, el carguero inglés Cakmoor, el pecio de la Hélice y pecio de la Caldera Nueva; o el mercante denominado pecio del Puerto de Pajares o pecio de la Sal.

Como se ha mencionado con anterioridad, el patrimonio arqueológico subacuático se encuentra gravemente amenazado por diversas actividades legítimas como las grandes obras de infraestructura que repercuten en gran medida en su deterioro o destrucción, siempre que se ejecuten sin el establecimiento de las medidas necesarias para la salvaguarda de este patrimonio.

Así, la gran industrialización costera del Campo de Gibraltar, efectuada sobre todo entre 1965-1985, o la creación del puerto de Algeciras en el año 1906 y su posterior transformación, conllevaron importantes elementos generadores de impacto medioambiental como movimientos de tierras, rellenos, alteraciones en la dinámica marina, etc., acciones que provocaron una importante afección sobre el patrimonio arqueológico existente en la zona, provocando bien la ocultación o imposibilidad de acceso a yacimientos, o su destrucción total.

En lo que se refiere a la afección sobre el patrimonio arqueológico, los primeros años de construcción, tanto de las distintas industrias como de la red de carreteras asociadas a las mismas, supusieron la destrucción total o parcial de importantes yacimientos terrestres y subacuáticos. Así, para el tramo marítimo afectado existen noticias orales que señalan la aparición de restos arqueológicos durante la ejecución de algunas de estas construcciones.

La localización de materiales arqueológicos, durante los numerosos controles arqueológicos efectuados en la zona, desde el año 1999, con motivo de la realización de obras de infraestructura, viene a atestiguar la importancia arqueológica de la zona, y es testimonio de la pérdida o destrucción de elementos arqueológicos que se encontrarían asociados a los actualmente localizados.

De esta forma, las actuaciones arqueológicas preventivas que se vienen desarrollando con motivo de las diversas obras de infraestructura ejecutadas en la zona constituyen, hoy en dia, un pilar fundamental para la protección e investigación del patrimonio arqueológico existente en este ámbito geográfico.

En definitiva, se trata de un abundante e importante patrimonio que debemos disfrutar pero ante todo debemos proteger. No hay

\section{Este importante y frágil patrimonio}

se encuentra gravemente amenazado

por diversas actividades legítimas

(construcción de gaseoductos, puertos

comerciales, parques eólicos marítimos...)

que inciden negativamente sobre el

medio marino en general y sobre el

cultural en particular

que olvidar que el patrimonio arqueológico debe ser entendido como un recurso no renovable y como tal merece ser estudiado desde el punto de vista científico. Su investigación y conservación aportan al conjunto de la sociedad importantes conocimientos sobre nuestra historia y permiten su disfrute común.

Es importante tener presente que hay que preservar los valores materiales y culturales en beneficio de todos, evitando situaciones que dificulten o desvirtúen su correcta interpretación. Se justifica sin duda la restricción del usufructo si su uso o emplazamiento entrañan peligro para su integridad. De este modo se garantiza que la información científica y la riqueza patrimonial que aporta el patrimonio que alberga el Campo de Gibraltar estarán a disposición del público a medio y largo plazo, gracias al esfuerzo de todos.

\section{Bibliografía}

CASTILLO BELINCHÓN, R. (2003) Control arqueológico de los movimientos de tierras de las obras de dragado necesarias para la ampliación del pantalán de la Refinería Gibraltar (San Roque, Cádiz). En Anuario Arqueológico de Andalucía III. Sevilla: Consejería de Cultura, vol. I, 2003, pp. 214-223

DECRETO 262/2007, de 16 de octubre, por el que se aprueba el Plan Rector de Uso y Gestión del Parque Natural del Estrecho y se modifica el Plan de Ordenación de los Recursos Naturales del frente litoral Algeciras-Tarifa, aprobado por Decreto 308/2002, de 23 de diciembre. Boletín Oficial de la Junta de Andalucia, n. 233 de 27 de noviembre de 2007

GARABELLO, R. (2004) La convenzione UNESCO sulla protezione del patrimonio culturale subacqueo. Milano: Giuffré, 2004

GARCíA RIVERA, C.; ALZAGA GARCÍA, M. (2008) La Carta Arqueológica Subacuática de Andalucía como instrumento para la tutela de un patrimonio

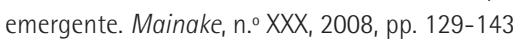

GONZÁLEZ GALLERO, R.; SAN CLAUDIO SANTA CRUZ, M.; FERNÁNDEZ MATALLANA, F. (2003) Prospección Arqueológica Subacuática con sondeos frente a la Colonia de Puente Mayorga (San Roque). En Anuario Arqueológico de Andalucia III, vol. I, 2003, pp. 208-213

LIBRO Verde del Plan Nacional de Protección del Patrimonio Cultural

Subacuático Español. Ministerio de Cultura, 2010

PEARSON, C. (1987) Conservation of marine archaeological objects. London; Boston: Butterworths, 1987 